Michael Eldred:

\title{
Introduction to Reputation in the Cyberworld
}

Reputation is a very familiar phenomenon. Your reputation is who you are held to be by others; it is your social standing. A good reputation is helpful for getting through life, and, in one sense or another, is indispensable for rising through the social ranks. For some career paths, notoriety may actually boost your standing in the world. Your reputation precedes you as the information or narrative in circulation about who you have been, so there is an undeniable connection to the temporal dimension of the past. Your very identity is tied to the reputation you have established or ruined in your personal social world.

In business transactions reputation can play a crucial role, especially where credit is required to finance them. A creditor has to trust a potential debtor, thus giving him credit in the double sense. Whether we trust each other in any kind of social interplay depends on each other's reputations in circulation that have come to our ears. Reputations apply to both natural and juridical persons. Any corporate entity will be jealous of its reputation because it has a direct link to commercial success. The growing phenomenon of Corporate Social Responsibility evidences how important a company's standing in the community and society has become, including for the bottom line. Companies' reputations have long since been drawn into political struggles over fair corporate practices.

The internet has been a game-changer in opening up an entirely new, artificial, digital world - the cyberworld - in which reputations of persons and companies circulate, reified as bit-strings. Your very identity - who you are - is today tied to bit-strings in circulation that have some connection to your proper name. Hence the desire of some to hide their identity in the cyberworld by means of pseudonyms or anonymization, whereas for others, the cyberworld provides an unprecedented opportunity for showing off who they are and launching their reputation more widely, even worldwide. The ease with which bit-strings relating to personal identity can be brought into circulation in the global digital matrix allows reputations and even fame to be promoted without the backing of specific media corporations. These used to function as gatekeepers who assessed whose reputation was worthy of dissemination and whose was not. Similarly, companies now employ the cyberworld to advertise not just products and services, but to promote who they are. Even name- or brand-recognition is a vital component of commercial success. Only because company names and brands are intimately linked to reputation are they so jealously guarded. The cyberworld opens a new arena for debating companies' reputations and social standing.

\section{Questions raised include:}

How does digitized reputation relate to 'normal' reputation, to human freedom? to truth? to rhetoric? Will the loss of digitized reputation, or the failure to establish one, amount to a kind of social death, of social non-existence in our brave new cyberworld?

Is the possibility - and thus power - of talking about someone in the third person a fundamental form of social violence and of the ineluctable social power play?

How is the striving to establish a reputation related to the will to power?

How can reputation be damaged by and how can it be protected against slander, libel, calumny, rumour and the like? How are these latter phenomena to be characterized? Are only legal means available to protect reputation?

How are personal reputation and corporate reputation different?

Do online social media enhance or impede, further or endanger the establishment of personal reputation?

Do pseudonyms in the cyberworld (legitimately?) enable flexible and/or multiple reputations - versatile plays with masks of identity?

How does reputation provide a lever for achieving a fair power play in civil society?

Who has control over my reputation in the cyberworld, if bit-strings 'never die' and companies gather and store my personal digital trace? Is my cyber-reputation inescapable?

How do companies' strategies to establish and enhance reputation via Corporate Social Responsibility offer also a point of attack in the power play of civil society to make companies change corporate policies and practices? 
Can public debate in the cyberworld over a company's reputation serve to constrain corporate practices in lieu of legal frameworks that have trouble being enforced on a global level?

How does the phenomenon of reputation change across cultures and how do the rules of play for establishing or losing reputation shift?

The present thematic issue of IRIE on Reputation in the Cyberworld presents a range of articles from various disciplines, countries and perspectives which touch upon, directly or indirectly, some of the questions posed above. I think each of these peer-reviewed articles speaks for itself. 